\title{
Microcrystalline Silicon Thin Film Deposition from Silicon Tetrafluoride: Isolating Role of Ion Energy using Tailored Voltage Waveform Plasmas
}

\author{
Junkang Wang ${ }^{1}$, Dmitri Daineka ${ }^{1}$, Mustapha Elyaakoubi ${ }^{2}$ and Erik V. Johnson ${ }^{1}$ \\ ${ }^{1}$ LPICM, CNRS, École Polytechnique, Université Paris Saclay, 91128, Palaiseau, France \\ ${ }^{2}$ TFSC-Instrument, 91120 Palaiseau, France
}

\begin{abstract}
The energy of ions during plasma enhanced chemical vapor deposition (PECVD) is known to impact material quality, but isolating this effect from other process parameters (plasma density, pressure) in a capacitively coupled plasma (CCP) is not straightforward. In this work, we utilize a novel radio-frequency (RF) excitation technique - tailored voltage waveforms (TVW) - as a solution to achieve ion flux-energy decoupling through the electrical asymmetry effect. This makes it possible to independently study the impact of ion energy on material deposition. We study the impact of ion energy - more precisely the maximum ion bombardment energy $\left(I B E_{\max }\right)$ before collisions - on the PECVD of hydrogenated microcrystalline silicon ( $\mu \mathrm{c}-\mathrm{Si}: \mathrm{H}$ ) thin films from an $\mathrm{SiF}_{4} / \mathrm{H}_{2} / \mathrm{Ar}$ chemistry. Through structural and electronic analysis, we find that the variation of $I B E_{\max }$ directly translates into material quality, even at relatively high process pressure. Better material properties (crystalline grain features, material density and photoelectronic response) are obtained for films deposited with moderate values of $I B E_{\max }$ around $45-55 \mathrm{eV}$. Above this range, a deterioration in material quality is observed, presumably due to more effective bulk atomic displacements induced by the silicon-containing ions. These results are consistent with the performance of single-junction $\mu \mathrm{c}-\mathrm{Si}: \mathrm{H}$ solar cell devices using these materials as active layers. Optimum performance is obtained for devices with an absorber layer deposited using a plasma excitation resulting in $I B E_{\max }$ in the range of $\sim 45-55 \mathrm{eV}$. The variation in device performance is mainly due to changes in the open circuit voltage.
\end{abstract}

Keywords: hydrogenated microcrystalline silicon, tailored voltage waveform, ion bombardment energy, ion-related interaction

\section{Introduction}

In contrast to hydrogenated amorphous silicon (a-Si:H), hydrogenated microcrystalline (or nanocrystalline) silicon ( $\mu \mathrm{c}-\mathrm{Si}: \mathrm{H})$ allows light absorption in the infrared due to its lower band-gap. It also shows better optoelectronic stability under light exposure, and it currently holds the record for a single-junction thin film silicon solar cell [1]. However, limited by the indirect band-gap, it usually requires several microns of $\mu \mathrm{c}-\mathrm{Si}: \mathrm{H}$ absorber layer to sufficiently absorb the light for single-junction solar cells, and even thicker for multi-junction devices to achieve current matching. The growth of high-quality $\mu \mathrm{c}-\mathrm{Si}: \mathrm{H}$ is typically performed using the conventional radio-frequency $(13.56 \mathrm{MHz})$ 
plasma enhanced chemical vapor deposition (RF-PECVD) technique. However, the higher RF power injection used to achieve elevated deposition rates also inevitably increases the ion bombardment energy $(I B E)$ during processing, often leading to a deterioration in material quality. To overcome this inherent limitation, the best known strategies are to use high process pressures [2,3], very high frequency (VHF) excitation [4,5], or "classical" dual-frequency excitation [6,7]. Nevertheless, additional problems such as a narrow process window, powder formation, inhomogeneity, frequency coupling and the cost of more complex deposition systems then need to be addressed.

The use of tailored voltage waveforms (TVW) to drive a plasma has been proven effective in decoupling the ion energy and the ion flux towards the electrodes in a capacitively coupled plasma (CCP) system [8-11]. Driven by a non-sinusoidal voltage waveform generated as a finite Fourier series of multiple consecutive harmonics with individually adjustable amplitudes and phases, an electrically asymmetric plasma response can be formed, regardless of the reactor geometry. As a consequence, a non-zero DC self-bias $\left(V_{D C}\right)$ can be established in such a discharge, even if it is operated in a geometrically symmetric reactor. By tuning the phase shift $\varphi$ between the harmonics, different types of voltage waveforms with controllably asymmetric minimum and maximum excursions (called an amplitude asymmetry) can be produced. To a first approximation, an almost continuous scanning of the ion energy at the electrodes can be achieved by controlling this amplitude asymmetry, while other process parameters are influenced very little. This is referred to as the Electrical Asymmetry Effect [12], which has been developed based on the pioneering work of Wendt et al. [13]. In a very short amount of time, it has been shown by several groups that TVW's can be of great interest for microelectronic processes [14-20], including the PECVD of $\mu \mathrm{c}-\mathrm{Si}: \mathrm{H}$ films for photovoltaic applications. For instance, control over the $I B E$ via the amplitude asymmetry effect can be helpful to understand and control $\mu \mathrm{c}-\mathrm{Si}: \mathrm{H}$ film growth morphology [14], material properties [15,16], and the resulting solar cell device performance [17]. Moreover, the use of TVW's has also been demonstrated to be helpful in solving the issue of deteriorated uniformity with increasing excitation frequencies [18].

In this work, we apply the TVW technique to a specific plasma chemistry, namely the use of a $\mathrm{SiF}_{4} / \mathrm{H}_{2} / \mathrm{Ar}$ gas mixture, previously developed to deposit high quality $\mu \mathrm{c}-\mathrm{Si}: \mathrm{H}$ films [21]. We report on the structural and electronic properties of $\mu \mathrm{c}-\mathrm{Si}: \mathrm{H}$ films deposited using this gas mixture, while using TVW plasma excitation to control the ion energy during deposition. The performance of single-junction solar cell devices with these intrinsic $\mu \mathrm{c}-\mathrm{Si}: \mathrm{H}$ layers incorporated as the absorber is also examined.

\section{Experimental details}

The experiments have been carried out in a CCP RF-PECVD reactor, which comprises a cylindrical plasma confinement box surrounding two $100 \mathrm{~mm}$ diameter parallel electrodes with their inter-electrode distance set to $20 \mathrm{~mm}$. The plasma box is grounded, thus making the chamber geometrically asymmetric. The two electrodes are vertically positioned during processing to minimize the impact from powders formed in the gas phase on the material deposition. Both electrodes are heated by resistive coils controlled via feedback loops, with temperatures monitored by embedded thermocouples.

The driving waveforms have been produced by a feedback-controlled arbitrary function generator 
and amplifier, as presented in detail previously in [15]. The voltage signal applied to the powered electrode can be expressed by

$$
V(t)=V_{0} \sum_{k=1}^{n} \frac{n-k+1}{n} \cos (k \omega t+\varphi)
$$

where $V_{0}$ is the voltage amplitude prefactor, $n$ is the number of harmonics (here set to four), and $\omega$ is the angular frequency, corresponding to the fundamental frequency at $13.56 \mathrm{MHz}$. Figure 1 shows some examples for such voltage waveforms with $n$ set to four, where $V_{\min }$ and $V_{\max }$ are the minimum and maximum excursions in the applied voltage. A phase shift $\varphi=0$ gives a peak type waveform, while $\varphi=0.5 \pi$ gives a sawtooth type and $\varphi=\pi$ gives a valley type. One can further increase $\varphi$ above $\pi$ up to $2 \pi$. In that case, another set of voltage waveforms having the same shape will be obtained, but with reversed positive and negative excursions.

Note that no matching network has been used in the current study, which means that a large fraction of the power is reflected (90-95\%) [22]. However, solutions for multi-frequency impedance matching systems are in practice available for this technique, as proposed by Franek et al. [23] in a system using multiple sources, and by Johnson and Booth [24,25] as a single, broadband power source system.
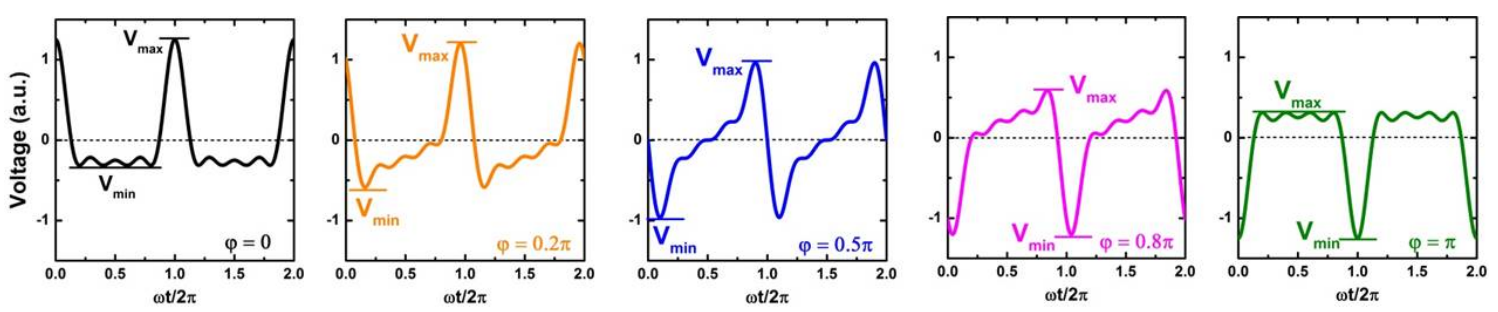

Figure 1. Voltage waveforms obtained with equation (1) for different values of $\varphi$ (in the range of $0-\pi$ ), with $n$ set to four. $V_{\min }$ and $V_{\max }$ represent the minimum and maximum amplitude of the applied signal.

In this work, the material deposition has been performed on Corning "Eagle" glass, with co-deposited films on undoped crystalline silicon (c-Si) wafers for further characterization. The phase between harmonics $\varphi$ was varied in the range from $0-2 \pi$, generating different shapes of TVW, while a constant value of $V_{P P}$ of $250 \mathrm{~V}$ was used. Following the work of Dornstetter et al. [26] on silicon thin film deposition from a $\mathrm{SiF}_{4} / \mathrm{H}_{2} / \mathrm{Ar}$ plasma chemistry using standard single-frequency $(13.56 \mathrm{MHz})$ excitation source, $\mathrm{SiF}_{4}, \mathrm{H}_{2}$ and Ar flow rates were chosen as $3.6 \mathrm{sccm}, 5 \mathrm{sccm}$ and $88 \mathrm{sccm}$, respectively, with a gas pressure of 3 Torr. The temperature of the grounded electrode was set to 150 ${ }^{\circ} \mathrm{C}$, and that of the powered electrode was $80{ }^{\circ} \mathrm{C}$.

The microstructure of the deposited films was characterized by ex-situ spectroscopic ellipsometry (UVISEL-Horiba Jobin Yvon) through measurements in the spectral range of 1.5-4.5 eV. To fit an optical model to the experimental data, a three-layer structure consisting of an interface layer, a bulk layer and a surface roughness layer was used. Each layer was modelled as a mixture of amorphous silicon [27], polycrystalline silicon [28] and voids, with the Bruggeman effective medium approximation (BEMA) used to calculate the response of these mixtures. The parameters allowed to change in the fitting process are the thickness and the volume fraction of each material in each layer. A further explanation of the ellipsometric modeling can be found in [29]. Raman scattering spectroscopy (LabRAM ARAMIS-Horiba Scientific) with excitation at $633 \mathrm{~nm}$ was also used to determine the 
crystalline volume fraction of the films. As described in [30], in order to accurately fit the experimental data, deconvolution of the Raman spectra with four Gaussian peaks located at $\sim 520 \mathrm{~cm}^{-1}$, $\sim 510 \mathrm{~cm}^{-1}, \sim 500 \mathrm{~cm}^{-1}$ and $\sim 480 \mathrm{~cm}^{-1}$ was performed. By fitting these four peaks, it is possible to calculate the Raman crystalline volume fraction $X_{c}^{\text {Raman }}$ through

$$
X_{c}^{\text {Raman }}=\left(\frac{I_{b}+I_{s c}+I_{c}}{I_{a}+I_{b}+I_{s c}+I_{c}}\right)
$$

where $I_{a}, I_{b}, I_{s c}$ and $I_{c}$ are the integrated peak intensities of the amorphous, grain boundaries, small crystallites and crystalline phase, respectively. Infrared absorption spectra were analyzed for the films using a Fourier transform infrared (FTIR) spectrometer (Thermo Nicolet 6700), revealing the details of hydride vibrations within the material. The steady-state photocarrier grating (TFSC instrument SSPG-230) measurements were performed at room temperature to characterize the films' transport properties. Coplanar aluminum contacts with a $1 \mathrm{~mm}$ gap were evaporated on top of the films deposited on glass substrates, and all the samples were annealed at $125^{\circ} \mathrm{C}$ for one hour after contact deposition.

The $\mu \mathrm{c}-\mathrm{Si}: H$ layers (with fluorine concentration less than $0.1 \%$ [31]) have been incorporated into single junction solar cell devices in a substrate $n-i-p$ configuration. The silicon layer stacks, composed of $n$-a-Si:H $/ i-\mu \mathrm{c}-\mathrm{Si}: \mathrm{H} / p-\mu \mathrm{c}-\mathrm{Si}: \mathrm{H}$, were deposited on a textured $\mathrm{ZnO}: \mathrm{Al} / \mathrm{Ag}$ rear contact (and back-reflector). The $p$ and $n$-doped layers were deposited using standard a single-frequency (13.56 $\mathrm{MHz}$ ) excitation source in another monochamber plasma reactor, described elsewhere [32]. The front contact was made of sputtered ITO, and a mask of $4 \mathrm{~mm}$ diameter was used to define the cells during the sputtering process. The ellipsometry measurements were performed on the co-deposited layers on glass to estimate the thicknesses of intrinsic absorber layers $\left(t_{i}\right)$. To study the electrical performance, the current density-voltage $(J-V)$ characteristics of the devices have been recorded under AM1.5G illumination with a commercial solar simulator (Oriel AAA), calibrated using a crystalline Si reference cell, and the external quantum efficiency (EQE) has been measured with the system calibrated by a silicon detector (Newport 10900).

\section{Results and discussion}

\subsection{Control over ion bombardment energy}

As this study deals with the impact of ion energy on $\mu \mathrm{c}-\mathrm{Si}: \mathrm{H}$ film growth, it is necessary to make an estimation of the time-averaged plasma potential $\left(V_{p l}\right)$, as this will be the maximum kinetic energy, i.e., the maximum $I B E\left(I B E_{\max }\right)$, that an ion may acquire before arriving on the growing surface (on the grounded electrode). Rather than measuring the $V_{p l}$ directly in a deposition plasma environment, it can be approximately estimated using $V_{D C}$ via [33]:

$$
V_{p l}=\frac{\left|V_{\min }\right|}{V_{P P}}\left(\frac{\left|V_{\max }\right|}{V_{P P}} V_{P P}+V_{D C}\right)
$$

where $\left|V_{\min }\right|+\left|V_{\max }\right|=V_{P P}$. The validity of equation (3) has been verified by Particle-In-Cell (PIC) simulation for an Ar plasma. Even for the case of multi-gas plasma like the $\mathrm{SiH}_{4} / \mathrm{H}_{2}$ plasma that is commonly used for silicon thin film deposition, the error made in the estimation remains at a relative low value (several volts) [33]. 
The value of $V_{D C}$ has been recorded during processing to estimate the corresponding $I B E_{\max }=q V_{p l}$, where $q$ is the elementary charge. Figure 2 shows the variation of $V_{D C}$ and $I B E_{\max }$ as a function of $\varphi$. Since the reactor is geometrically asymmetric due to the grounded plasma box, large negative values of $V_{D C}$ are usually observed, as shown in Figure 2-(a). With $\varphi$ increasing from 0 to $\pi, V_{D C}$ presents an almost linear increase, whereas an opposite trend is observed when $\varphi$ ranges from $\pi$ to $2 \pi$. Accordingly, control over the $I B E_{\max }$ between $\sim 20 \mathrm{eV}$ and $\sim 70 \mathrm{eV}$ (with a similar trend as that for $V_{D C}$ ) is obtained, as shown in Figure 2-(b).

Figure 2-(b) also provides the deposition rate $\left(r_{d}\right)$ of the films. On the whole, $r_{d}$ shows a "W"-shape trend with two maxima at $\varphi=0$ (or $2 \pi$, peak waveform) and $\varphi=\pi$ (valley waveform) Such a dependency on $\varphi$ has also been observed in a previous study about the deposition of a-Si:H [34], and likely originates from the $\varphi$-dependent power coupling when $V_{P P}$ is kept constant, as confirmed by previous PIC simulations [33].
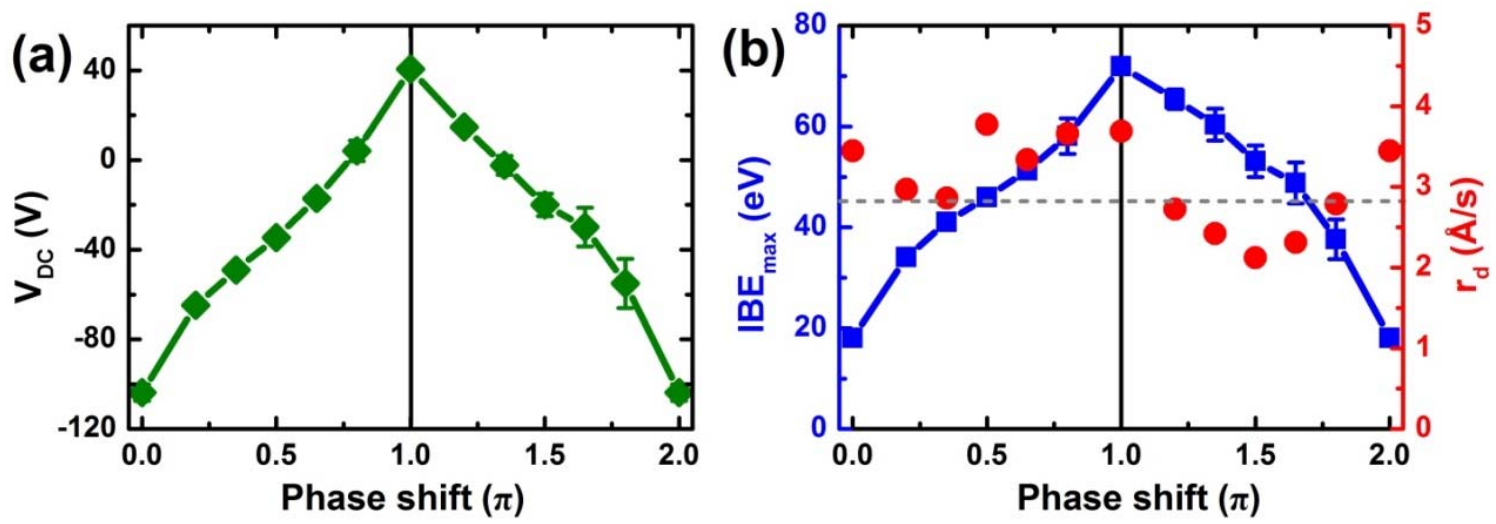

Figure 2. (a) Experimentally obtained $V_{D C}$ as a function of $\varphi$ during $\mu \mathrm{c}-\mathrm{Si}: \mathrm{H}$ film deposition. (b) Variation of the estimated $I B E_{\max }$ and $r_{d}$ with varying $\varphi$. The gray dash line is a guide to eye for the comparison of $r_{d}$.

However, upon closer inspection, this "W"-shape is not perfectly symmetric. One can note that the films deposited by the voltage waveforms with $\varphi$ below $\pi$ (for the sake of simplicity, hereafter, the films deposited with values of $\varphi$ in the range from $0-\pi$ will be referred as the " $0-\pi$ " films) always present higher deposition rates than their counterparts (correspondingly, " $\pi-2 \pi$ " films), as highlighted by the gray dashed line of Figure 2-(b). This is especially noticeable for the cases using the special group of sawtooth waveforms ( $\varphi=0.5 \pi$ or $1.5 \pi$ ), having no amplitude asymmetry but just opposite voltage rising and falling slopes [35]. A $r_{d}$ of $3.8 \AA / \mathrm{s}$ is observed at $\varphi=0.5 \pi$, while with a significant lower value of $2.1 \AA / \mathrm{s}$ for its counterpart at $\varphi=1.5 \pi$. The difference in ion energies cannot be the main reason for this, as similar $I B E_{\max }$ values $(\sim 40-50 \mathrm{eV})$ are found for both cases. This discrepancy in deposition rate is therefore likely linked to the slope asymmetry effect generated through the utilization of amplitude symmetric sawtooth waveforms, examined in detail in Ref. [36-38].

\subsection{Structural properties}

To quantify the impact of ion energy, the films have been characterized by Raman spectroscopy, and the results are presented in Figure 3. Upon initial inspection, the Raman spectra of these films are quite similar (see Figure 3-(a), only the " $0-\pi$ " films are shown). Although the film deposited at $\varphi=\pi$ (valley) 
shows a shift of the peak position, (which may indicate stress in the material [39]) a pronounced Raman crystalline peak around $520 \mathrm{~cm}^{-1}$ is observed for all these films. After deconvolution, similar values of $X_{c}^{\text {Raman }}$ on the order of $\sim 70-75 \%$ are obtained, regardless of any difference in process conditions.

Despite the small difference in crystalline volume fraction, a more significant effect of ion energy conditions can be revealed by looking at the full width at half maximum of crystalline peak at $520 \mathrm{~cm}^{-1}$ $\left(\mathrm{FWHM}_{520}\right)$ extracted from the Raman spectra. Figure 3-(b) shows the variation of $\mathrm{FWHM}_{520}$ as a function of $I B E_{\max }$. It can be observed that the $\mathrm{FWHM}_{520}$ shows an upward trend with increasing $I B E_{\max }$ above a threshold around 45-55 eV. When $I B E_{\max }$ is below $\sim 45-55 \mathrm{eV}, \mathrm{FWHM}_{520}$ remains relatively constant at low values around $6.5 \mathrm{~cm}^{-1}$. A sharp rise is observed when ion energy increases above $\sim 45-55 \mathrm{eV}$, reaching a value of $\mathrm{FWHM}_{520}$ around $8.7 \mathrm{~cm}^{-1}$ at $I B E_{\max }=\sim 70 \mathrm{eV}$. This suggests that although similar crystalline volume fractions are obtained for all process conditions, high ion energy conditions can lead to the growth of smaller grained material [40].
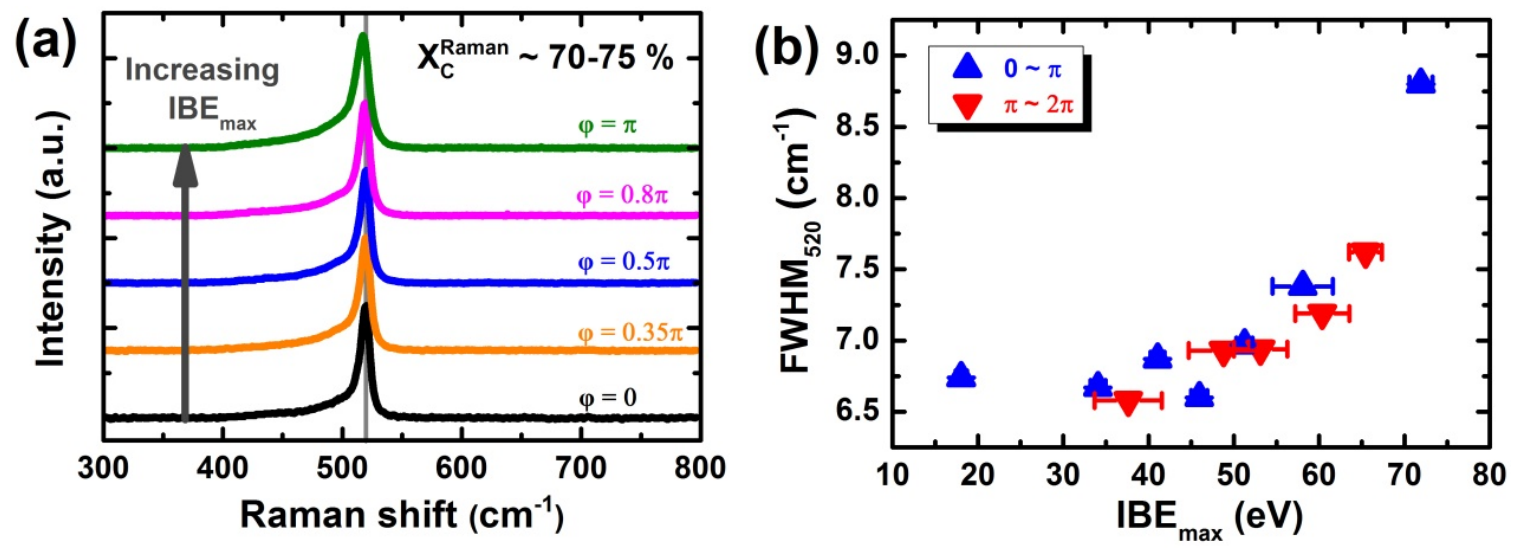

Figure 3. (a) Raman spectra for $\mu \mathrm{c}-\mathrm{Si}: \mathrm{H}$ films deposited using different types of TVW (only the " $0-\pi$ " films are shown). The gray line indicates the silicon Raman crystalline peak at $\sim 520 \mathrm{~cm}^{-1}$. (b) Variation of FWHM $_{520}$ with varying $I B E_{\max }$, where the up/down triangles correspond to the " $0-\pi$ " “ $\pi-2 \pi$ " films, respectively.

Ellipsometry measurements have also been performed, and Figure 4-(a) shows the comparison of the ellipsometry spectra for these films (only the " $0-\pi$ " films are shown). The results confirm the crystalline phase dominant material as seen by Raman measurements. The clear shoulder-like peaks at $3.4 \mathrm{eV}$ and $4.2 \mathrm{eV}$ (characteristic of microcrystalline silicon) are observed for all these films. However, one can see that the relative magnitude of the spectra at these points differs from each other. In Figure 4-(b), the comparison of the maximal $\left\langle\varepsilon_{i}>\left(<\varepsilon_{i}\right\rangle_{\max }\right)$ in the high energy portion for these films is presented. An increase with $I B E_{\max }$ is observed, up to values of $\sim 45-55 \mathrm{eV}$. A monotonic decrease is then observed for higher ion energies $\left(I B E_{\max }>\sim 45-55 \mathrm{eV}\right)$. It is worth noticing that this threshold


depends on a number of factors: the crystalline volume fraction, crystallite size, density, as well as surface roughness. Regardless of the reason, a greater $\left\langle\varepsilon_{i}\right\rangle_{\max }$ is commonly considered to be associated with improved material properties [41].

Interesting enough, one can note from the results that the " $\pi-2 \pi$ " films always present a higher value of $\left\langle\varepsilon_{i}\right\rangle_{\max }$ than their counterparts, despite similar ion energy conditions. However, Raman 
measurements show that all these films present similar values of $X_{c}^{\text {Raman }}$, and no obvious difference in the tendency of $\mathrm{FWHM}_{520}$ with increasing $I B E_{\max }$ is observed between these two series (Figure 3-(b)).
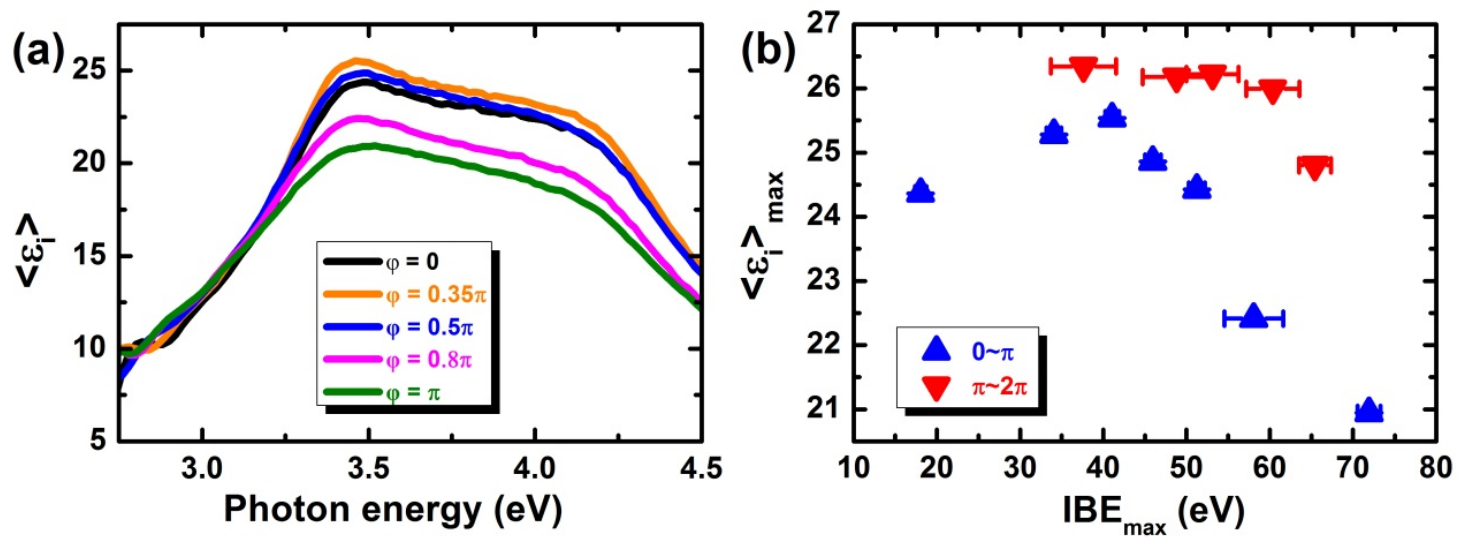

Figure 4. (a) Ellipsometry spectra in high energy portion for $\mu \mathrm{c}-\mathrm{Si}: \mathrm{H}$ films deposited using different TVW (only the "0- $\pi$ " films are shown). (b) Variation of the $\left\langle\varepsilon_{i}\right\rangle_{\max }$ at high energy portion with varying $I B E_{\max }$.

In order to get a clearer physical picture from the ellipsometry spectra, optical modeling has been conducted. Figure 5 summarizes the effect of ion energy conditions on the surface roughness, crystalline volume fraction (small and large grains), and void content in the bulk layer for the deposited films. It can be noted from Figure 5-(a) that the surface roughness decreases slightly with increasing $I B E_{\max }$ up to $\sim 45-55 \mathrm{eV}$, then increases for higher ion energies. However, one can see a striking difference between the two sets of films, namely a higher surface roughness is obtained for the " $0-\pi$ " films. This behavior mirrors that of Figure 4-(b), and so one can reasonably state that the surface roughness is the dominant factor that determines the magnitude of ellipsometry spectra, $\left\langle\varepsilon_{i}\right\rangle_{\max }$, including its lower values for case of the " $0-\pi$ " films, as observed in Figure 4-(b) $[42,43]$.

In Figure 5-(b), the variation of the small and large crystalline grain volume fraction (i.e., $X_{s g}^{S E}$ and $\left.X_{l g}^{S E}\right)$ are presented. One can note that the total crystalline volume fraction $\left(X_{c}^{S E}=X_{s g}^{S E}+X_{l g}^{S E}\right)$ deduced from the ellipsometric model is approaching $100 \%$ ("fully crystallized"), which differs from that obtained from Raman measurements $\left(X_{c}^{\text {Raman }}=\sim 70 \%\right.$ ). Similar results have also been observed in Ref. [44]. In that work, different process conditions lead to an increase of $X_{c}^{\text {Raman }}$ from $\sim 60 \%$ up to $\sim 80 \%$, while the $X_{c}^{S E}$ stays roughly constant at $100 \%$ (void content not considered, but assumed to be at a low level). The discrepancy between these two techniques could originate from the portion of small grains that are indistinguishable from the amorphous phase by Raman scattering. This underestimation of crystalline volume fraction in $\mu \mathrm{c}-\mathrm{Si}: \mathrm{H}$ films by Raman measurement has also been reported by a number of groups [45,46]. Limited by the fitting method, the presence of a broad tail at low wavenumbers (due to the a-Si:H tissue) for a $\mu \mathrm{c}-\mathrm{Si}: \mathrm{H}$ Raman spectra usually leads to $X_{c}^{\text {Raman }}$ less than $90 \%$, even with a $100 \%$ crystallinity from X-Ray Diffraction (XRD) measurement [47].

Nevertheless, one can see from Figure 5-(b) that the dependencies of $X_{s g}^{S E}$ and $X_{l g}^{S E}$ on $I B E_{\max }$ are similar for both sets of films, namely a continuous increase of $X_{s g}^{S E}$ and decrease of $X_{l g}^{S E}$ with increasing $I B E_{\max }$. These results are consistent with the Raman analysis that smaller grained material is obtained at high ion energies (Figure 5-(b)), although the threshold values observed are not exactly the same.

The consistency between the Raman and ellipsometry results is further confirmed when comparing 
the FWHM ${ }_{520}$ of the Raman spectra with the evolutions of $X_{s g}^{S E}$ and $X_{l g}^{S E}$, as determined by spectroscopic ellipsometry. As one can see in Figure 6, a broader Raman peak (increasing FWHM 520 ) correlates well with a greater small grain fraction $\left(X_{s g}^{S E}\right)$ and a lesser large grain fraction $\left(X_{l g}^{S E}\right)$. Globally, the highest FWHM $_{520}$ and lowest $X_{l g}^{S E}$ are obtained at the highest ion energy conditions.

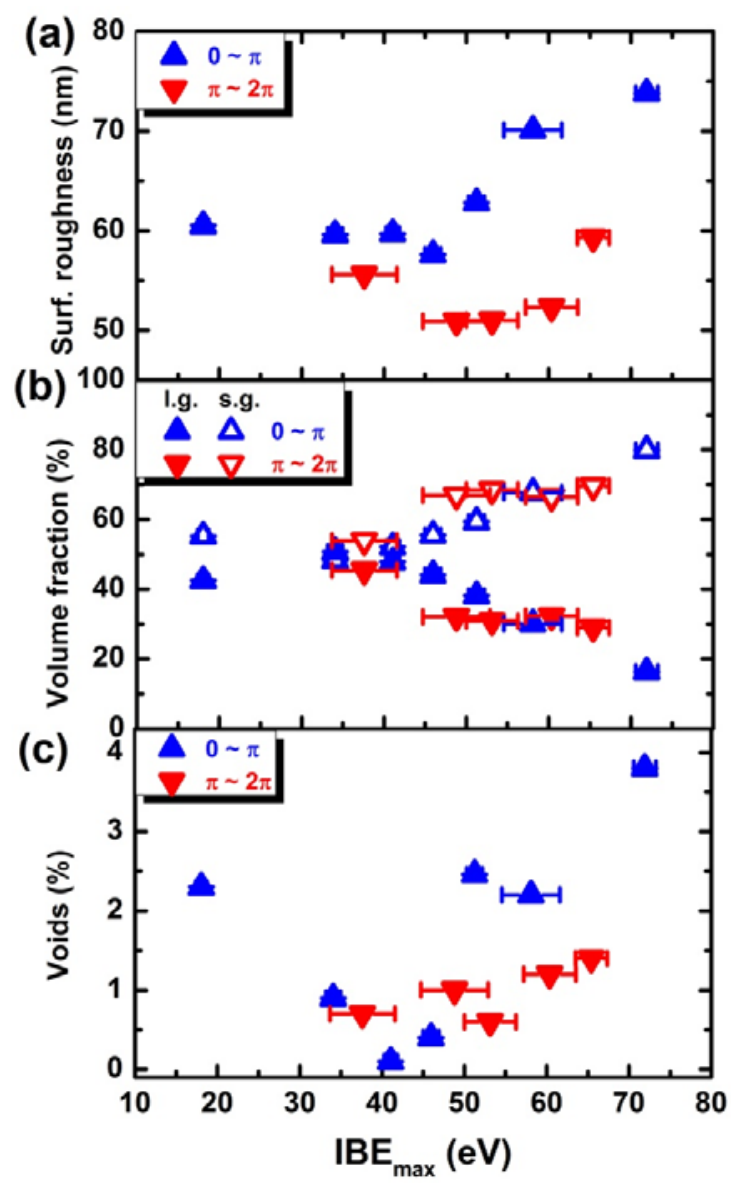

Figure 5. Variation of (a) surface roughness, (b) small and large grain volume fraction, i.e., $X_{s g}^{S E}$ and $X_{l g}^{S E}$, and (c) void fraction $X_{v}^{S E}$ in bulk layer with varying $I B E_{\max }$.

Finally, in Figure 5-(c), the variation of void fraction $\left(X_{v}^{S E}\right)$ in the bulk layer for these films deposited under different ion energy conditions is also presented. It shows that $X_{v}^{S E}$ decreases until $I B E_{\max }$ reaches $\sim 45-55 \mathrm{eV}$, and then starts to increase again. Therefore, a moderate ion energy condition $\left(I B E_{\max }=\sim 45-55 \mathrm{eV}\right)$ during processing can lead to the improvement of bulk layer density. It is important to note that this tendency cannot be observed using Raman spectroscopy, as the void fraction does not contribute to the Raman spectrum. However, this result can be confirmed through other characterization techniques, as will be done in the following section. 


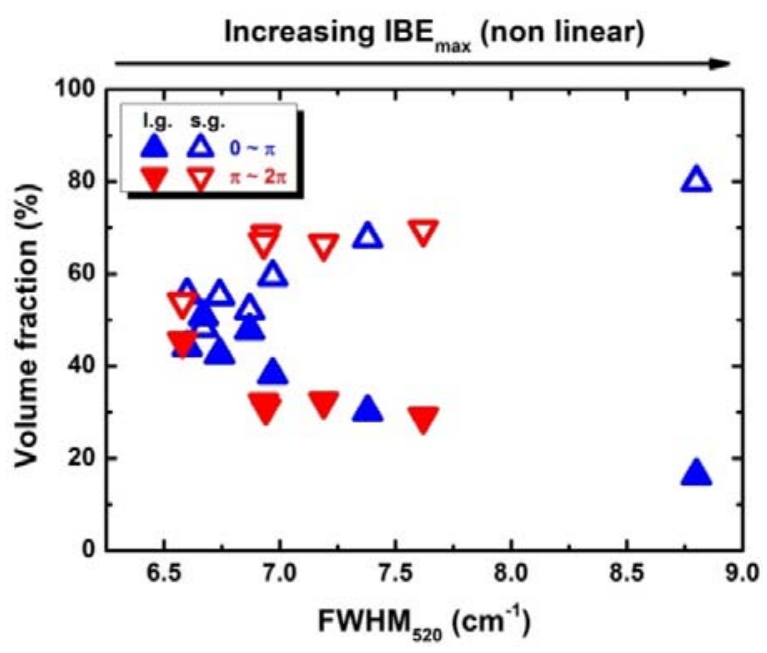

Figure 6. Correlation between fraction of small/large grain in bulk layer and $\mathrm{FWHM}_{520}$.

\subsection{Infrared absorption}

Figure 7 shows the FTIR absorption spectra of the co-deposited " $0-\pi$ " films on c-Si wafers, focusing on the hydride stretching modes (SMs) $[48,49]$. It is generally believed that the SMs can be classified into two groups, namely the low SM (LSM, at $\sim 1980-2030 \mathrm{~cm}^{-1}$ ) and the high SM (HSM, at $\sim 2060-2160 \mathrm{~cm}^{-1}$ ). Both the LSM and HSM are related to the a-Si:H tissue in the material. Specifically, the LSM is assigned to hydrogen bonded in vacancies and that of the HSM to the hydride groups incorporated at the surface of internal nanosized voids [50].

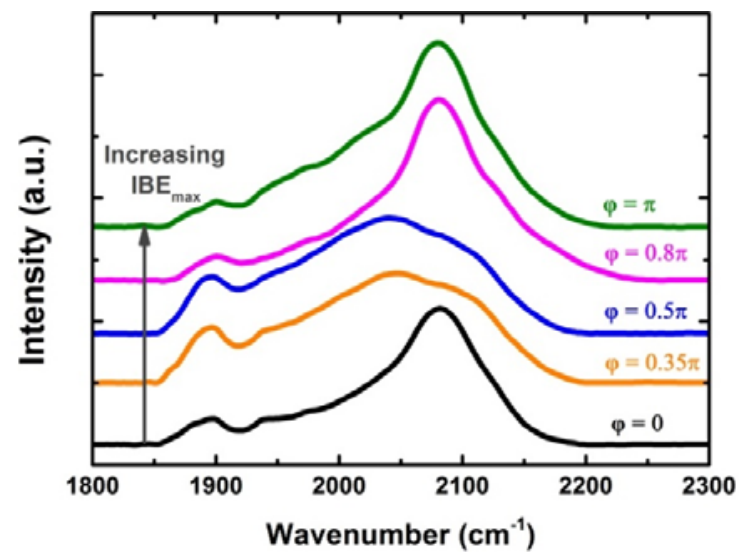

Figure 7. FTIR spectra in range from 1800 to $2300 \mathrm{~cm}^{-1}$ for $\mu \mathrm{c}-\mathrm{Si}: \mathrm{H}$ films deposited using different types of TVW (only the " $0-\pi$ " films are shown).

It can be observed that the film deposited under the lowest ion energy conditions ( $\varphi=0$, peak) exhibits a dominant HSM in the spectra. When slightly higher ion energy conditions are used, the signature of LSM starts to appear $(\varphi=0.35 \pi)$, and becomes more pronounced for further increased ion energy ( $\varphi=0.5 \pi$, sawtooth). However, once the highest ion energy conditions are used $(\varphi>0.5 \pi)$, the smaller grained material (observed from Raman and ellipsometry analysis) present prominent HSM again. A similar tendency is observed for the " $\pi-2 \pi$ " films (not shown here). 
In order to make a qualitative evaluation of the material microstructure, a microstructure parameter $R^{*}$ can be derived from the FTIR spectra. This $R^{*}$ is defined by the ratio between the integrated absorption intensity of HSM and the sum of LSM and HSM, i.e., $I_{H S M} /\left(I_{L S M}+I_{H S M}\right)$ [51]. It has been shown a lower value of $R^{*}$ indicates a denser material, from which the resulting $\mu \mathrm{c}-\mathrm{Si}: \mathrm{H}$ solar cell device of optimum performance can be obtained [52].

Figure 8 shows the variation of $R^{*}$ for this series of $\mu \mathrm{c}-\mathrm{Si}: \mathrm{H}$ films as a function of $I B E_{\max }$, in which a clear transition can be noted: a moderate increase of $I B E_{\max }$ from $\sim 20 \mathrm{eV}$ up to $\sim 50 \mathrm{eV}$ leads to a continuous decrease from 0.75 down to 0.3 . Once the $I B E_{\max }$ is above this specific value, a dramatic increase of $R^{*}$ back up to 0.8 at $I B E_{\max }=\sim 60 \mathrm{eV}$ is observed. Again, this $I B E_{\max }$ threshold coincides with the values detected by Raman and ellipsometry measurements. Looking back at Figure 3(a), for the films deposited with $I B E_{\max }$ higher than $\sim 45-55 \mathrm{eV}$, an increase of $\mathrm{FWHM}_{520}$ was observed, while the crystalline volume fraction kept almost constant. This indicates that a greater proportion of smaller grains present in the film. A similar trend has also been observed from the ellipsometry modeling results, as shown in Figure 5. Therefore, a larger density of internal nanosized voids associated with the grain boundaries is expected for those films, leading to more of the associated hydride groups, and thus an increase in $R^{*}$.

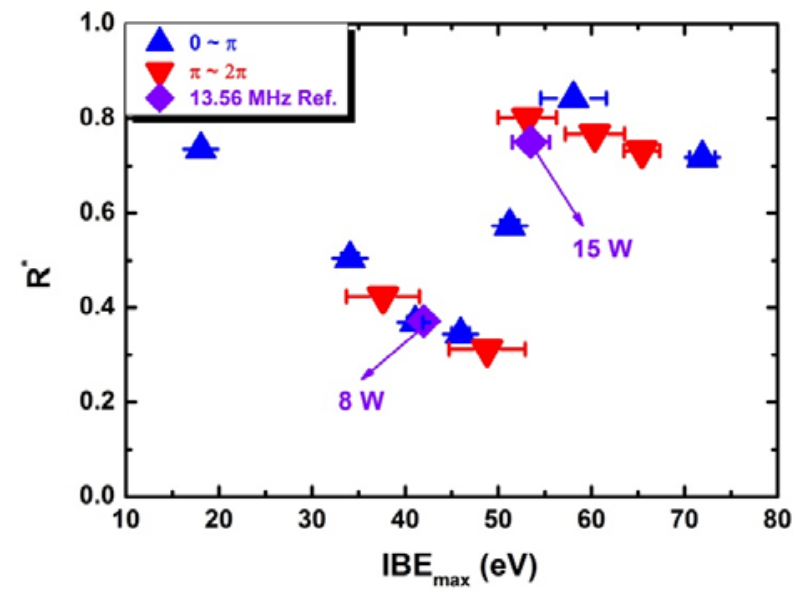

Figure 8. Variation of microstructure parameter $R^{*}$ with varying $I B E_{\max }$. Two reference films deposited using standard single-frequency (13.56 MHz) excitation source with low (8 W) and high (15 W) power are shown by purple diamonds.

In addition, we have deposited two reference films using a standard single-frequency $(13.56 \mathrm{MHz})$ excitation source. The process conditions are shown in Table 1: one of them $(15 \mathrm{~W})$ is similar to the conditions used in Ref. [53] for the deposition of the intrinsic absorber layer for high efficiency $\mu \mathrm{c}-\mathrm{Si}: \mathrm{H}$ solar cell devices; for the other one, we attempted to decrease the RF power to achieve a lower ion energy during deposition. The $V_{D C}$ has been recorded, and according to equation (3), the $I B E_{\max }$ during the deposition of these two films are determined to be $\sim 53.5 \mathrm{eV}(15 \mathrm{~W})$ and $\sim 42 \mathrm{eV}(8 \mathrm{~W})$, respectively.

The deduced $R^{*}$ values for these two films are included in Figure 8 for comparison. It can be observed that the results fit quite well in the trend with increasing $I B E_{\max }$. Therefore, reducing the power injection could be a way to decrease the ion energy during deposition, thus making it possible to achieve improved material properties. However, one should note that this would lead to a sacrifice in 
deposition rate compared to the case of high power injection. As presented in Table 1, the deposition rate reduces from $2.46 \AA / \mathrm{s}$ at $15 \mathrm{~W}$ down to $1.43 \AA / \mathrm{s}$ at $8 \mathrm{~W}$, showing an almost $40 \%$ drop.

Table 1. Process conditions for two reference $\mu \mathrm{c}-\mathrm{Si}: \mathrm{H}$ films deposited using standard single-frequency (13.56 $\mathrm{MHz}$ ) excitation source. $P_{R F}$ represents the RF power injection.

\begin{tabular}{cccccc}
\hline \hline $\boldsymbol{P}_{\boldsymbol{R} \boldsymbol{F}}$ & $\boldsymbol{V}_{\boldsymbol{P P}}$ & $\boldsymbol{V}_{\boldsymbol{D C}}$ & $\boldsymbol{I B E}_{\text {max }}$ & $\boldsymbol{X}_{\boldsymbol{c}}^{\text {Raman }}$ & $\boldsymbol{r}_{\boldsymbol{d}}$ \\
\hline $\mathrm{W}$ & $\mathrm{V}$ & $\mathrm{V}$ & $\mathrm{eV}$ & $\%$ & $\AA / \mathrm{s}$ \\
\hline 15 & 285 & -35.5 & $\sim 53.5$ & 73 & 2.46 \\
8 & 212 & -22 & $\sim 42$ & 67 & 1.43 \\
\hline \hline
\end{tabular}

\subsection{Ion-related interactions}

In contrast to neutrals, ions within the plasma can have a considerable amount of kinetic energy due to the acceleration process in the plasma sheath. A great deal of studies have shown that such energetic ions can play a vital role in determining the properties of PECVD-deposited silicon thin films, such as hydrogen bonding configuration [54], defect density [55], surface morphology [33], as well as optoelectronic properties [56-60]. This is due to the interactions between the impinging ions with the growing surface, such as producing local thermal spikes and/or inducing atomic displacements. The extent to which the deposited material can be affected depends on a number of factors: the ions' kinetic energy, the mass ratio between ions and target atoms, as well as the ions' angle of incidence. Furthermore, due to the collisional plasma sheath under high pressure conditions (for instance, several Torr in this work), only a small fraction of ions can arrive the growing surface with the maximum kinetic energy, $I B E_{\max }$. However, previous studies have shown that the growth of $\mu \mathrm{c}-\mathrm{Si}: \mathrm{H}$ can be significantly affected even by that small proportion of ions having $I B E_{\max }$ [33].

To illustrate the mechanism that leads to similar threshold values of $I B E_{\max }$ for the various $\mu \mathrm{c}-\mathrm{Si}: \mathrm{H}$ material properties observed in this work, we consider the mass-dependent ion-related interactions during processing. In Figure 9, the theoretical energy thresholds at which impinging ions begin to induce effective surface and bulk atomic displacement on a silicon substrate are plotted versus the ion mass [61]. We will use this to examine which ions are most likely to be responsible for the changes in material properties observed in the previous section, and which display a threshold value between 45 and $55 \mathrm{eV}$, indicated as the red band in Figure 9.

In the plasma process studied in this work, the ions most likely to be present in the plasma are $\mathrm{H}_{\mathrm{x}}{ }^{+}$ $(\mathrm{x}=0-3), \mathrm{Ar}^{+}$and $\mathrm{SiF}_{\mathrm{x}}{ }^{+}(\mathrm{x}=0-3)$. As reported in Ref. [14], $\mathrm{H}_{3}{ }^{+}$-induced bulk displacement has a crucial impact on the $\mu \mathrm{c}-\mathrm{Si}: \mathrm{H}$ film growth dynamics as well as surface morphology. As a result, the nucleation process on the amorphous incubating layer is hindered, leading to the growth of smaller grained material. However, the ion energy threshold for this displacement process is around $65 \mathrm{eV}$, which is well above the experimentally obtained values in this work (indicated by the red band). On the other hand, the threshold for the $\mathrm{H}_{3}{ }^{+}$-induced surface displacement is around $30 \mathrm{eV}$. Even though such surface displacement will be present when the $I B E_{\max }$ is greater than this value, no sharp change in material properties is observed at this threshold value.

The ion energy threshold for the $\mathrm{Ar}^{+}$-induced surface displacement is around $12 \mathrm{eV}$, which means 
that this process is equally present for all the plasma conditions studied in this work. Therefore, this ion is not the source of the transitions in material properties. Bulk displacement can also occur if the ion energy is high enough $\left(I B E_{\max }>\sim 35 \mathrm{eV}\right)$. However, as for the $\mathrm{H}_{3}{ }^{+}$-induced surface displacement, no obvious transition is observed due to this ion-surface interaction.

Finally, the $\mathrm{SiF}_{\mathrm{x}}{ }^{+}$species present can be $\mathrm{Si}^{+}, \mathrm{SiF}^{+}, \mathrm{SiF}_{2}{ }^{+}$, and $\mathrm{SiF}_{3}{ }^{+}$, of which have surface displacement energy thresholds in the range of $12-15 \mathrm{eV}$, and so like $\mathrm{Ar}^{+}$-induced surface displacement, are present for all conditions. Concerning bulk displacement, the thresholds are $36 \mathrm{eV}, 43 \mathrm{eV}, 50 \mathrm{eV}$, and $55 \mathrm{eV}$ respectively. Of these, only $\mathrm{Si}^{+}$lies clearly below the threshold energy for changes in material (red band of Figure 9). However, each or all the other $\mathrm{SiF}_{\mathrm{x}}^{+}$could be responsible for the ion-related changes in material properties.

Doubtlessly, larger silicon-containing ions with more than one Si atom, i.e., $\mathrm{Si}_{\mathrm{y}} \mathrm{F}_{\mathrm{x}}{ }^{+}(\mathrm{y}>1)$ will be present in such high-pressure plasma processes, and will inevitably have some impact on the film growth. However, one should note that higher numbers of atoms within the ions would favor elastic collisions upon contact with target atoms, thus the energy transfer could be much less effective. Furthermore, as larger molecules will tend to charge negatively, the relative density of $\mathrm{Si}_{y} \mathrm{~F}_{\mathrm{x}}{ }^{+}$species with $\mathrm{x}, \mathrm{y}>3$ are negligible compared to single $\mathrm{Si}$ ions. Concretely, the range of ion masses for those $\mathrm{Si}_{\mathrm{y}} \mathrm{F}_{\mathrm{x}}{ }^{+}$is within 75-150 amu, as indicated by the shadowed area in gray. Their required surface displacement energies are all below $\sim 20 \mathrm{eV}$, and so will be equally present for all plasma conditions. On the other hand, some of the $\mathrm{Si}_{\mathrm{y}} \mathrm{F}_{\mathrm{x}}{ }^{+}$species (like $\mathrm{Si}_{2} \mathrm{~F}^{+}$and $\mathrm{Si}_{2} \mathrm{~F}_{2}{ }^{+}$) could mimic $\mathrm{SiF}_{3}{ }^{+}$and similarly contribute (through bulk displacement) to the threshold effect on film growth.

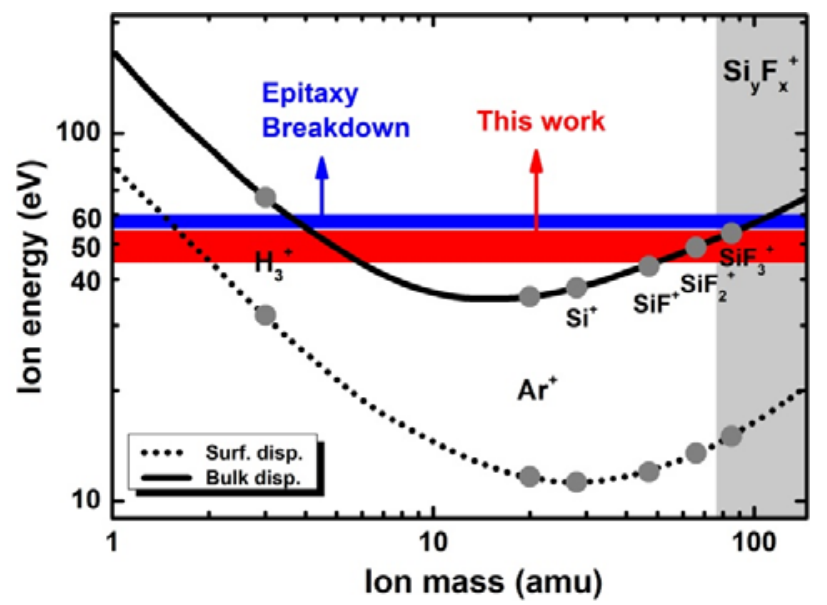

Figure 9. Energy threshold for ion-induced surface (dashed line) and bulk (solid line) atomic displacement on a silicon substrate versus impinging ion mass, calculated by Brice et al. [61]. The $\mathrm{H}_{3}{ }^{+}, \mathrm{Ar}^{+}$and $\mathrm{SiF}_{\mathrm{x}}{ }^{+}$-induced displacements are highlighted (circles), and higher order silicon-related ions $\left(\mathrm{Si}_{\mathrm{y}} \mathrm{F}_{\mathrm{x}}{ }^{+}, \mathrm{y}>1\right)$ are indicated by the shadow area in gray. The blue and red bands correspond to the upper limit of $I B E_{\max }$ to sustain silicon epitaxy (from Ref. [62]) and the experimental threshold values found in this work.

In summary, $\mu \mathrm{c}-\mathrm{Si}: \mathrm{H}$ film deposition under moderate ion energy conditions with $I B E_{\max }=\sim 45-55$ $\mathrm{eV}$ can be helpful to suppress the formation of nanovoids, and thus to deposit dense material, as indicated by the reduction of $X_{v}^{S E}$ and a drop of $R^{*}$. This can be understood by considering the different surface processes related to the impinging ions. However, local defects and poor electronic properties will be induced if the ion energy is above a certain threshold. The experimentally observed 
transitions of material properties are most likely to be associated with the silicon-related ion-induced bulk atomic displacements. As a consequence, crystallite growth is severely hindered, thus leading to the formation of smaller grained materials with deteriorated electronic properties.

Interestingly, in a previous study concerning the study of silicon epitaxy using similar process conditions on the same reactor, it has been proposed that stable epitaxial growth can be sustained only when $I B E_{\max }$ is below $58 \mathrm{eV}$, and epitaxy breakdown occurs instantly if it is above $60 \mathrm{eV}$ (guided by the blue band) [62]. This critical value is in good agreement with the experimental observations in this work.

\section{Electronic properties and integration into solar cells}

\subsection{Transport properties}

To examine the impact of ion energy on the films' electronic properties, SSPG measurements have been carried out. In combination with the structural properties studied previously, these results can be useful to determine the most appropriate process conditions for active layer deposition in solar cell devices. Herein, two sets of films with different thicknesses $(0.5 \mu \mathrm{m}$ and $1 \mu \mathrm{m})$ were deposited under different ion energy conditions. For comparison, reference films $(13.56 \mathrm{MHz}, 15 \mathrm{~W}, 0.5 \mu \mathrm{m})$ have also been deposited.

The minority carrier diffusion length $\left(L_{d}\right)$ for these two sets of films can be extracted from SSPG measurements, and the results are shown in Figure 10-(a). On the whole, the thicker films $(1 \mu \mathrm{m})$ present a higher $L_{d}$ than the thinner ones. This can be understood by considering the coplanar configuration of measurements and the columnar growth of $\mu \mathrm{c}-\mathrm{Si}: \mathrm{H}$. Because of the material anisotropy along the growth direction, giving improved grain features (larger grain sizes), and less influence from the bottom amorphous incubation layer (or less crystallized layer in the early growth stage), thicker films can lead to a better photoelectronic response. More interestingly, one can note from these results that the evolution of $L_{d}$ with increasing $I B E_{\max }$ for both sets of films follows the tendencies observed in the material structural properties. Guided by the curves on the graphs, one can note that $L_{d}$ shows a continuous increase with increasing $I B E_{\max }$ up to moderate values $(\sim 45 \mathrm{eV})$, and then decreases for higher ion energies.
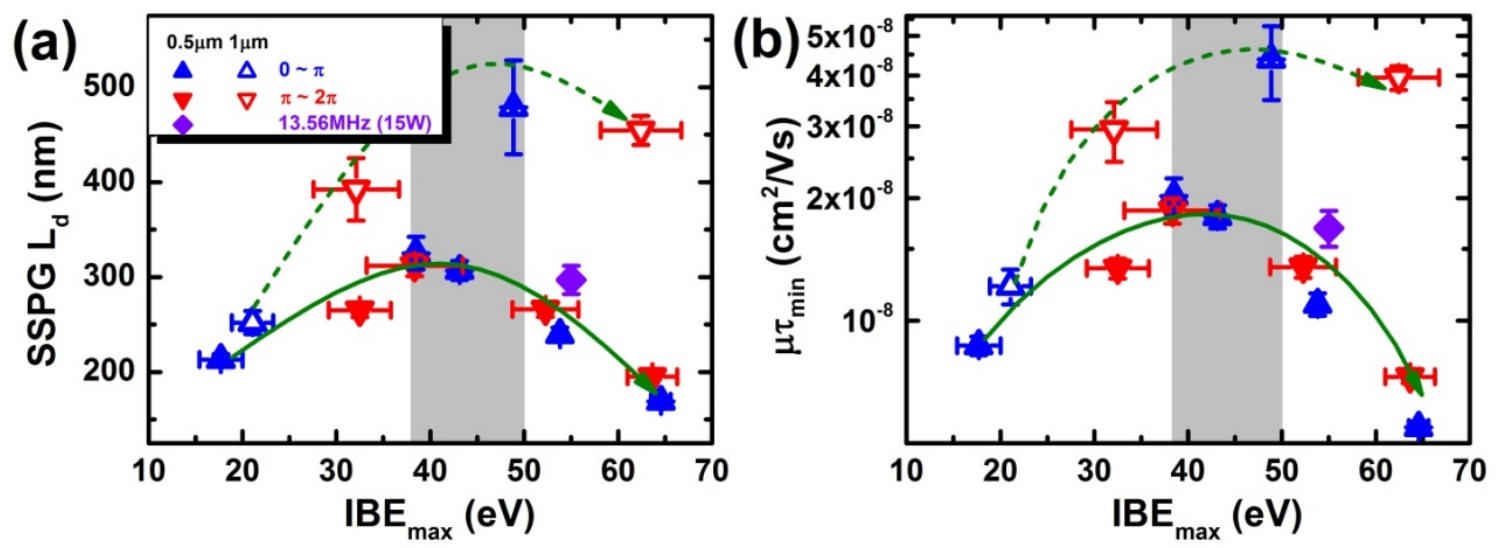

Figure 10. Variation of (a) $L_{d}$ and (b) $\mu \tau_{\min }$ at room temperature for two sets of $\mu \mathrm{c}-\mathrm{Si}: \mathrm{H}$ films with varying 
$I B E_{\max }$. The solid and open triangles correspond to films with $0.5 \mu \mathrm{m}$ and $1 \mu \mathrm{m}$ thickness, respectively.

The purple diamond corresponds to the $0.5 \mu \mathrm{m}$ thick reference film.

The measured value for the reference film is also shown in Figure 10-(a) (purple diamond). Notably, it fits quite well within the trend. Moreover, SSPG measurements allows for the determination of the ambipolar mobility-lifetime products (holes mobility-lifetime products, $\mu \tau_{\text {min }}$ ) through [63]:

$$
\mathrm{L}_{\mathrm{d}}=\sqrt{2 \frac{\mathrm{q}}{\mathrm{kT}} \mu \tau_{\min }}
$$

Figure 10-(b) presents the results of $\mu \tau_{\min }$ plotted with increasing $I B E_{\max }$. In line with $L_{d}$, similar trends are observed for $\mu \tau_{\min }$.

\subsection{Substrate $n-i-p \mu c-S i: H$ solar cells}

The previous section demonstrated that the coplanar transport properties of $\mu \mathrm{c}-\mathrm{Si}: \mathrm{H}$ grown from $\mathrm{SiF}_{4}$ are predictably sensitive to $I B E_{\max }$. However, the "out-of-plane" transport properties will be more crucial for practical solar cell devices. To test the performance of these layers in devices, a series of substrate $n-i-p$ structure single-junction solar cells were prepared, incorporating a TVW plasma-deposited intrinsic $\mu \mathrm{c}-\mathrm{Si}: \mathrm{H}\left(I B E_{\max }=\sim 20-65 \mathrm{eV}\right)$ film as the absorber layer. To make a comparison, a reference device has also been prepared.

It should be noted that this study is only focused on the impact of the quality of intrinsic layer on the resulting device performance, and no special attention has been paid to the optimization of the doped layers. Moreover, the doped and intrinsic layers have been deposited in different PECVD reactors, necessitating vacuum breaks at both the $n / i$ and $p / i$ interfaces. For these samples, the $p$-layer outside of the ITO contact for each sub-cell is not removed. Even though the $p$-layer is more resistive than the ITO, it can still lead to an increased collection area in the case of light $J-V$ measurements. In order to minimize this impact and to better define the active area, the samples have been covered during light $J-V$ measurements with the same type of shadow mask as was used for the deposition of ITO. The calibration of the light source was double-checked by calculating the $J_{S C}$ from the EQE spectrum (sample values are indicated in the table).

Figure 11 presents the light $J-V$ characteristics for this series of solar cells, and the detailed performance parameters $\left(V_{O C}, J_{S C}, F F\right.$ and $\eta$ ) are summarized in Table 2. Some trends can be noted from these results. (i) With the increase of ion energy, $J_{S C}$ remains at a relative stable value around 23.0 $\mathrm{mA} / \mathrm{cm}^{2}$ (similar values are deduced from EQE, see Table 2) up to $I B E_{\max }=\sim 55 \mathrm{eV}$ (reference sample). It should be noted that a slightly thinner absorber layer is used for $I B E_{\max }=\sim 45 \mathrm{eV}$ (see Table 2), with little impact on $J_{S C}$. (ii) Further increase in ion energy leads to a fast decay of device performance, indicated by the dramatic decrease of $J_{S C}$ down to $4.3 \mathrm{~mA} / \mathrm{cm}^{2}$ at $I B E_{\max }=\sim 65 \mathrm{eV}$. (iii) In contrast to the sharp change in $J_{S C}, V_{O C}$ shows a less dramatic but more sensitive dependence on the ion energy condition during processing. As presented in Table 2, with increasing ion energy, an increase in $V_{O C}$ is observed, with an optimum value of $0.509 \mathrm{~V}$ occurring at $I B E_{\max }=\sim 45 \mathrm{eV}$. However, a decrease is seen for the highest ion energies. Again, the result of the reference sample $\left(I B E_{\max }=\sim 55 \mathrm{eV}\right)$ fits well within the tendency. 


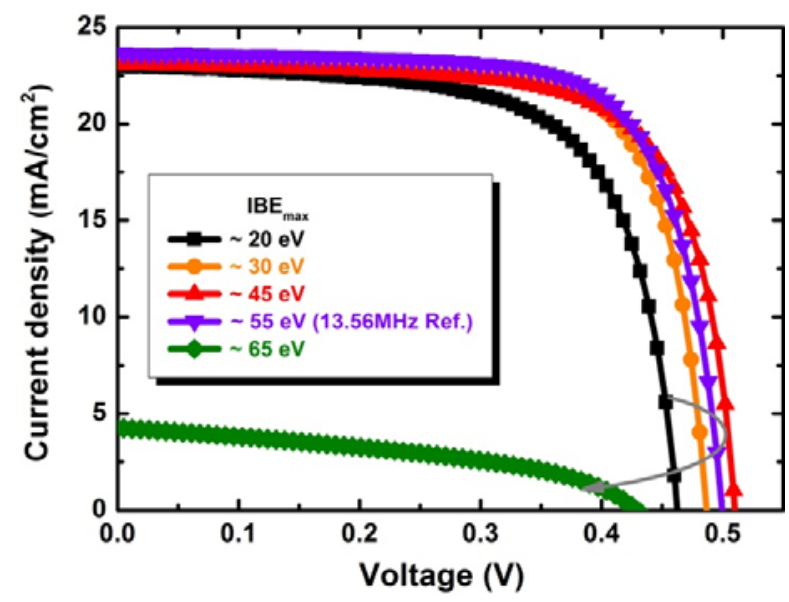

Figure 11. Light $J-V$ curves of $\mu \mathrm{c}-\mathrm{Si}: \mathrm{H}$ solar cells with absorber layers deposited using TVW, and with reference sample deposited by standard single-frequency $(13.56 \mathrm{MHz})$ excitation source shown in purple.

In order to access the physical properties of the photodiodes, $J-V$ measurements have also been performed in the dark, from which the dark saturation current density $J_{0}$ for these solar cells has been extracted. The results are also shown in Table 2. As can be seen, the improvement resulting from moderate ion energy conditions is rather noticeable. Lower values of $J_{0}$ around $2.5 \times 10^{-4} \mathrm{~mA} / \mathrm{cm}^{-2}$ are obtained with $I B E_{\max }$ at $\sim 45-55 \mathrm{eV}$. This is in comparison to an order of magnitude higher value obtained at lower ion energy conditions $\left(I B E_{\max }=\sim 20 \mathrm{eV}\right)$ and the doubly greater value obtained at the highest ion energy conditions $\left(I B E_{\max }=\sim 65 \mathrm{eV}\right.$ ). As in the simplest model for a solar cell, $V_{O C}$ is linked to $J_{0}$, this alone can account for the trend in $V_{O C}$.

Table 2. $J-V$ parameters of $\mu \mathrm{c}-\mathrm{Si}: \mathrm{H}$ solar cells with intrinsic absorber layers deposited under different ion energy conditions using TVW The reference cell $\left(I B E_{\max }=\sim 55 \mathrm{eV}\right)$ was deposited using standard single-frequency (13.56 MHz) excitation source with $15 \mathrm{~W}$ power injection.

\begin{tabular}{cccccccc}
\hline \hline $\boldsymbol{I B E}_{\boldsymbol{m a x}}$ & $\boldsymbol{t}_{\boldsymbol{i}}$ & $\boldsymbol{V} \boldsymbol{o \boldsymbol { C }}$ & $\boldsymbol{J}_{\boldsymbol{S C}}$ & $\boldsymbol{J}_{\boldsymbol{S C}}(\boldsymbol{E} \boldsymbol{Q E})$ & $\boldsymbol{F F}$ & $\boldsymbol{\eta}$ & $\boldsymbol{J}_{\boldsymbol{0}}$ \\
\hline $\mathrm{eV}$ & $\mu \mathrm{m}$ & $\mathrm{V}$ & $\mathrm{mA} / \mathrm{cm}^{2}$ & $\mathrm{~mA} / \mathrm{cm}^{2}$ & $\%$ & $\%$ & $\mathrm{~mA} / \mathrm{cm}^{2}$ \\
\hline$\sim 20$ & 1.25 & 0.460 & 23.0 & 22.7 & 68.0 & 7.19 & $1.6 \times 10^{-3}$ \\
$\sim 30$ & 1.25 & 0.488 & 23.5 & - & 72.6 & 8.32 & $4.6 \times 10^{-4}$ \\
$\sim 45$ & 1.15 & 0.509 & 23.1 & 23.4 & 71.6 & 8.42 & $2.5 \times 10^{-4}$ \\
$\sim 55$ (Ref.) & 1.45 & 0.502 & 23.6 & 23.6 & 72.3 & 8.58 & $2.8 \times 10^{-4}$ \\
$\sim 65$ & 1.45 & 0.432 & 4.3 & - & 41.7 & 0.77 & $5.7 \times 10^{-4}$ \\
\hline \hline
\end{tabular}

In summary, the impact of energetic ion bombardment during the deposition of intrinsic $\mu \mathrm{c}-\mathrm{Si}: \mathrm{H}$ absorber layer is reflected directly in the solar cell device performance, in line with the aforementioned material properties. Moderate ion bombardment during deposition leads to an improvement of $V_{O C}$. However, solar cell devices with the absorber layer deposited under excessively high ion energy conditions presented significantly degraded performance. This can be attributed to material deterioration induced by the bulk atomic displacement at high energies. One may also note that the reference process using a standard single-frequency $(13.56 \mathrm{MHz})$ excitation source can lead to similar 
ion energy conditions and comparable device performance. Nevertheless, the greater flexibility provided by the semi-independent control of plasma properties via TVW gives it an advantage, as it has the possibility to achieve higher deposition rates without sacrificing material properties.

\section{Conclusions}

In this work, we have applied the multi-frequency TVW excitation technique to the RF-PECVD of $\mu \mathrm{c}-\mathrm{Si}: \mathrm{H}$ films from an $\mathrm{SiF}_{4} / \mathrm{H}_{2} / \mathrm{Ar}$ plasma chemistry. Making use of the amplitude asymmetry in such non-sinusoidal voltage waveforms, a semi-independent control over the ion energy has been achieved, allowing us to isolate ion energy effects at an almost constant film growth rate. Through structural and electronic analysis, we find that a variation of ion energy - or precisely speaking the $I B E_{\max }$ - during processing can be of vital importance in depositing high quality materials.

Despite the relatively high process pressure (3 Torr), the impact of the small fraction of ions having $I B E_{\max }$ is revealed. The best film properties (crystalline grain features, material density and photoelectronic response) have been obtained with $I B E_{\max }$ around $45-55 \mathrm{eV}$. Beyond this range, a reduction in the material quality reflected by smaller crystallite features and a lower density is observed. This is attributed to the effect of bulk atomic displacements induced by silicon-related ions during processing.

We have established clear links between the controllable plasma parameters via TVW, to the properties of deposited materials, and eventually to their performance in photovoltaic devices. When such TVW plasma-deposited intrinsic $\mu \mathrm{c}-\mathrm{Si}: \mathrm{H}$ films are incorporated into solar cell devices, the impact of ion energy is reflected directly by the $J-V$ parameters. Single-junction $\mu \mathrm{c}-\mathrm{Si}: \mathrm{H}$ solar cells with an absorber layer deposited with $I B E_{\max }$ in the range of $\sim 45-55 \mathrm{eV}$ have shown an optimum performance, mainly due to an improvement in $V_{O C}$. These results demonstrate that making use of TVW for plasma excitation can be of much interest not only to optimize high quality materials, but indeed to developing an understanding of this optimization. This is of great value when developing materials for practical photovoltaic applications.

\section{Acknowledgements}

The work presented herein was funded by the Agence Nationale de la Recherche through the ANR projects “APOCALYPSO” (ANR-13-PRGE-0003-01) and "PERSIL” (ANR-16-CE05-0019). 


\section{References}

[1] H. Sai, T. Matsui, H. Kumagai, K. Matsubara, Thin-film microcrystalline silicon solar cells: 11.9\% efficiency and beyond, Appl. Phys. Express. 11 (2018) 022301. doi:10.7567/APEX.11.022301.

[2] L. Guo, M. Kondo, M. Fukawa, K. Saitoh, A. Matsuda, High Rate Deposition of Microcrystalline Silicon Using Conventional Plasma-Enhanced Chemical Vapor Deposition, Jpn. J. Appl. Phys. 37 (1998) L1116. doi:10.1143/JJAP.37.L1116.

[3] T. Roschek, T. Repmann, J. Müller, B. Rech, H. Wagner, Comprehensive study of microcrystalline silicon solar cells deposited at high rate using $13.56 \mathrm{MHz}$ plasma-enhanced chemical vapor deposition, J. Vac. Sci. Technol. A. 20 (2002) 492-498. doi:10.1116/1.1450585.

[4] H. Keppner, J. Meier, P. Torres, D. Fischer, A. Shah, Microcrystalline silicon and micromorph tandem solar cells, Appl. Phys. A. 69 (1999) 169-177. doi:10.1007/s003390050987.

[5] O. Vetterl, F. Finger, R. Carius, P. Hapke, L. Houben, O. Kluth, A. Lambertz, A. Mück, B. Rech, H. Wagner, Intrinsic microcrystalline silicon: A new material for photovoltaics, Sol. Energy Mater. Sol. Cells. 62 (2000) 97-108. doi:10.1016/S0927-0248(99)00140-3.

[6] H. Goto, M. Sasaki, T. Ohmi, T. Shibata, A. Yamagami, N. Okamura, O. Kamiya, Minimizing Wafer Surface Damage and Chamber Material Contamination in New Plasma Processing Equipment, Jpn. J. Appl. Phys. 29 (1990) L2395. doi:10.1143/JJAP.29.L2395.

[7] P.C. Boyle, A.R. Ellingboe, M.M. Turner, Independent control of ion current and ion impact energy onto electrodes in dual frequency plasma devices, J. Phys. Appl. Phys. 37 (2004) 697. doi:10.1088/0022-3727/37/5/008.

[8] Z. Donkó, J. Schulze, B.G. Heil, U. Czarnetzki, PIC simulations of the separate control of ion flux and energy in CCRF discharges via the electrical asymmetry effect, J. Phys. Appl. Phys. 42 (2009) 025205. doi:10.1088/0022-3727/42/2/025205.

[9] T. Lafleur, R.W. Boswell, J.P. Booth, Enhanced sheath heating in capacitively coupled discharges due to non-sinusoidal voltage waveforms, Appl. Phys. Lett. 100 (2012) 194101. doi:10.1063/1.4712128.

[10] J. Schulze, E. Schüngel, U. Czarnetzki, The electrical asymmetry effect in capacitively coupled radio frequency discharges - measurements of dc self bias, ion energy and ion flux, J. Phys. Appl. Phys. 42 (2009) 092005. doi:10.1088/0022-3727/42/9/092005.

[11] D.J. Economou, Tailored ion energy distributions on plasma electrodes, J. Vac. Sci. Technol. A. 31 (2013) 050823. doi:10.1116/1.4819315.

[12] G.H. Brian, C. Uwe, B. Ralf Peter, M. Thomas, On the possibility of making a geometrically symmetric RF-CCP discharge electrically asymmetric, J. Phys. Appl. Phys. 41 (2008) 165202. doi:10.1088/0022-3727/41/16/165202.

[13] S.-B. Wang, A.E. Wendt, Control of ion energy distribution at substrates during plasma processing, J. Appl. Phys. 88 (2000) 643-646. doi:10.1063/1.373715.

[14] B. Bruneau, M. Lepecq, J.K. Wang, J.-C. Dornstetter, J.-L. Maurice, E.V. Johnson, Effect of Ion 
Energy on Microcrystalline Silicon Material and Devices: A Study Using Tailored Voltage Waveforms, IEEE J. Photovolt. 4 (2014) 1354-1360. doi:10.1109/JPHOTOV.2014.2357259.

[15] E.V. Johnson, T. Verbeke, J.-C. Vanel, J.-P. Booth, Nanocrystalline silicon film growth morphology control through RF waveform tailoring, J. Phys. Appl. Phys. 43 (2010) 412001. doi:10.1088/0022-3727/43/41/412001.

[16] E. Schüngel, R. Hofmann, S. Mohr, J. Schulze, J. Röpcke, U. Czarnetzki, Evaluation of the Electrical Asymmetry Effect by spectroscopic measurements of capacitively coupled discharges and silicon thin film depositions, Thin Solid Films. 574 (2015) 60-65. doi:10.1016/j.tsf.2014.11.059.

[17] D. Hrunski, F. Mootz, A. Zeuner, A. Janssen, H. Rost, R. Beckmann, S. Binder, E. Schüngel, S. Mohr, D. Luggenhölscher, U. Czarnetzki, G. Grabosch, Deposition of microcrystalline intrinsic silicon by the Electrical Asymmetry Effect technique, Vacuum. 87 (2013) 114-118. doi:10.1016/j.vacuum.2012.02.020.

[18] D. Hrunski, A. Janssen, T. Fritz, T. Hegemann, C. Clark, U. Schreiber, G. Grabosch, The influence of the electrical asymmetry effect on deposition uniformity of thin silicon film, Thin Solid Films. 532 (2013) 56-59. doi:10.1016/j.tsf.2012.12.105.

[19] J.K. Wang, E.V. Johnson, Electrode-selective deposition/etching processes using an $\mathrm{SiF}_{4} / \mathrm{H}_{2} / \mathrm{Ar}$ plasma chemistry excited by sawtooth tailored voltage waveforms, Plasma Sources Sci. Technol. 26 (2017) 01LT01. doi:10.1088/0963-0252/26/1/01LT01.

[20] G. Fischer, E. Drahi, F. Lebreton, P. Bulkin, G. Poulain, E.V. Johnson, Nanotextured Silicon Surfaces using Tailored Voltage Waveform Plasmas: Impact of Ion Bombardment Energy on Etching Dynamics and Passivation, in: 33rd Eur. Photovolt. Sol. Energy Conf. Exhib., Amsterdam, 2017. doi:10.4229/EUPVSEC20172017-2AV.2.33.

[21] J.-C. Dornstetter, J. Wang, B. Bruneau, E.V. Johnson, P. Roca i Cabarrocas, Material and growth mechanism studies of microcrystalline silicon deposited from $\mathrm{SiF}_{4} / \mathrm{H}_{2} / \mathrm{Ar}$ gas mixtures, Can. J. Phys. 92 (2014) 740-743. doi:10.1139/cjp-2013-0606.

[22] T. Lafleur, P.A. Delattre, J.-P. Booth, E.V. Johnson, S. Dine, Radio frequency current-voltage probe for impedance and power measurements in multi-frequency unmatched loads, Rev. Sci. Instrum. 84 (2013) 015001. doi:10.1063/1.4773540.

[23] J. Franek, S. Brandt, B. Berger, M. Liese, M. Barthel, E. Schüngel, J. Schulze, Power supply and impedance matching to drive technological radio-frequency plasmas with customized voltage waveforms, Rev. Sci. Instrum. 86 (2015) 053504. doi:10.1063/1.4921399.

[24] E.V. Johnson, J.-P. Booth, Electrical circuit to impedance match a source and a load at multiple frequencies, method to design such a circuit, EP2675064A1, 2013.

[25] E.V. Johnson, J.-P. Booth, Circuit for Impedance Matching Between a Generator and a Load at Multiple Frequencies, Assembly Comprising Such a Circuit and Related Use, WO2018087189 (A1), 2018.

[26] J.-C. Dornstetter, B. Bruneau, P. Bulkin, E.V. Johnson, P. Roca i Cabarrocas, Understanding the amorphous-to-microcrystalline silicon transition in $\mathrm{SiF}_{4} / \mathrm{H}_{2} / \mathrm{Ar}$ gas mixtures, J. Chem. Phys. 140 (2014) 234706. doi:10.1063/1.4883503. 
[27] D.E. Aspnes, A.A. Studna, Dielectric functions and optical parameters of Si, Ge, GaP, GaAs, GaSb, InP, InAs, and InSb from 1.5 to 6.0 eV, Phys. Rev. B. 27 (1983) 985-1009. doi:10.1103/PhysRevB.27.985.

[28] G.E. Jellison, M.F. Chisholm, S.M. Gorbatkin, Optical functions of chemical vapor deposited thin-film silicon determined by spectroscopic ellipsometry, Appl. Phys. Lett. 62 (1993) 3348. doi:10.1063/1.109067.

[29] P.R. i Cabarrocas, Deposition Techniques and Processes Involved in the Growth of Amorphous and Microcrystalline Silicon Thin Films, in: W.G.J.H.M. van Sark, L. Korte, F. Roca (Eds.), Springer Berlin Heidelberg, Berlin, Heidelberg, 2012: pp. 131-160.

[30] J.-C. Dornstetter, S. Kasouit, P. Roca i Cabarrocas, Deposition of High-Efficiency Microcrystalline Silicon Solar Cells Using $\mathrm{SiF}_{4} / \mathrm{H}_{2} / \mathrm{Ar}$ Mixtures, IEEE J. Photovolt. 3 (2013) 581-586. doi:10.1109/JPHOTOV.2012.2221683.

[31] J.-C. Dornstetter, Microcrystalline silicon deposited from $\mathrm{SiF}_{4} / \mathrm{H}_{2} / \mathrm{Ar}$ plasmas and its application to photovoltaics, $\mathrm{PhD}$ thesis, Ecole Polytechnique, 2014.

[32] A. Dommann, N. Herres, M. Krink, J.J. Galiano, B. Stmpfli, Internal stresses and lifetime evaluation of PECVD isolating layers, Microsyst. Technol. 4 (2001) 161-164. doi:10.1007/s005420000081.

[33] B. Bruneau, J.K. Wang, J.-C. Dornstetter, E.V. Johnson, Growth mechanisms study of microcrystalline silicon deposited by $\mathrm{SiH}_{4} / \mathrm{H}_{2}$ plasma using tailored voltage waveforms, J. Appl. Phys. 115 (2014) 084901. doi:10.1063/1.4866693.

[34] J.K. Wang, C. Longeaud, F. Ventosinos, D. Daineka, M.E. Yaakoubi, E.V. Johnson, Deposition of a-Si:H thin films using tailored voltage waveform plasmas: impact on microstructure and stability, Phys. Status Solidi C. 13 (2016) 735-739. doi:10.1002/pssc.201600024.

[35] B. Bruneau, T. Novikova, T. Lafleur, J.-P. Booth, E.V. Johnson, Ion flux asymmetry in radiofrequency capacitively-coupled plasmas excited by sawtooth-like waveforms, Plasma Sources Sci. Technol. 23 (2014) 065010. doi:10.1088/0963-0252/23/6/065010.

[36] B. Bruneau, T. Gans, D. O'Connell, A. Greb, E.V. Johnson, J.-P. Booth, Strong Ionization Asymmetry in a Geometrically Symmetric Radio Frequency Capacitively Coupled Plasma Induced by Sawtooth Voltage Waveforms, Phys. Rev. Lett. 114 (2015) 125002. doi:10.1103/PhysRevLett.114.125002.

[37] S. Brandt, B. Berger, E. Schüngel, I. Korolov, A. Derzsi, B. Bruneau, E. Johnson, T. Lafleur, D. O'Connell, M. Koepke, T Gans, J.-P. Booth, Z. Donkó, J. Schulze, Electron power absorption dynamics in capacitive radio frequency discharges driven by tailored voltage waveforms in CF4, Plasma Sources Sci. Technol. 25 (2016) 045015. doi:10.1088/0963-0252/25/4/045015.

[38] A. Derzsi, B. Bruneau, A.R. Gibson, E. Johnson, D. O’Connell, Timo Gans, J.-P. Booth, Z. Donkó, Power coupling mode transitions induced by tailored voltage waveforms in capacitive oxygen discharges, Plasma Sources Sci. Technol. $26 \quad$ (2017) 034002. doi:10.1088/1361-6595/aa56d6.

[39] J. Kassabov, ed., Physical problems in microelectronics: proceedings of the Fourth International School, ISPPM, Varna, Bulgaria, 12-18 May 1985, World Scientific, Singapore; Philadelphia, 
1985.

[40] M.N. Islam, S. Kumar, Influence of crystallite size distribution on the micro-Raman analysis of porous Si, Appl. Phys. Lett. 78 (2001) 715. doi:10.1063/1.1343494.

[41] A. Abramov, P. Roca i Cabarrocas, K. Girotra, H. Chen, S. Park, K. Park, J. Huh, J. Choi, C. Kim, J.H. Souk, Reliable Characterization of Microcrystalline Silicon Films for Thin Film Transistor Applications, Jpn. J. Appl. Phys. 47 (2008) 7308-7310. doi:10.1143/JJAP.47.7308.

[42] Y. Djeridane, A. Abramov, P. Roca i Cabarrocas, Silane versus silicon tetrafluoride in the growth of microcrystalline silicon films by standard radio frequency glow discharge, Thin Solid Films. 515 (2007) 7451-7454. doi:10.1016/j.tsf.2006.11.112.

[43] A. Abramov, Y. Djeridane, R. Vanderhaghen, P. Roca i Cabarrocas, Large grain $\mu c-S i: H$ films deposited at low temperature: Growth process and electronic properties, J. Non-Cryst. Solids. 352 (2006) 964-967. doi:10.1016/j.jnoncrysol.2005.10.060.

[44] G. Viera, S. Huet, L. Boufendi, Crystal size and temperature measurements in nanostructured silicon using Raman spectroscopy, J. Appl. Phys. 90 (2001) 4175-4183. doi:10.1063/1.1398601.

[45] L. Houben, M. Luysberg, P. Hapke, R. Carius, F. Finger, H. Wagner, Structural properties of microcrystalline silicon in the transition from highly crystalline to amorphous growth, Philos. Mag. A. 77 (1998) 1447-1460. doi:10.1080/01418619808214262.

[46] C. Ossadnik, S. Vepřek, I. Gregora, Applicability of Raman scattering for the characterization of nanocrystalline silicon, Thin Solid Films. 337 (1999) 148-151. doi:10.1016/S0040-6090(98)01175-4.

[47] S. Klein, F. Finger, R. Carius, T. Dylla, B. Rech, M. Grimm, L. Houben, M. Stutzmann, Intrinsic microcrystalline silicon prepared by hot-wire chemical vapour deposition for thin film solar cells, Thin Solid Films. 430 (2003) 202-207. doi:10.1016/S0040-6090(03)00111-1.

[48] M.H. Brodsky, M. Cardona, J.J. Cuomo, Infrared and Raman spectra of the silicon-hydrogen bonds in amorphous silicon prepared by glow discharge and sputtering, Phys. Rev. B. 16 (1977) 3556-3571. doi:10.1103/PhysRevB.16.3556.

[49] G. Lucovsky, Chemical effects on the frequencies of Si-H vibrations in amorphous solids, Solid State Commun. 29 (1979) 571-576. doi:10.1016/0038-1098(79)90666-5.

[50] A.H.M. Smets, T. Matsui, M. Kondo, Infrared analysis of the bulk silicon-hydrogen bonds as an optimization tool for high-rate deposition of microcrystalline silicon solar cells, Appl. Phys. Lett. 92 (2008) 33503-33506. doi:10.1063/1.2837536.

[51] E. Bhattacharya, A.H. Mahan, Microstructure and the light-induced metastability in hydrogenated amorphous silicon, Appl. Phys. Lett. 52 (1988) 1587-1589. doi:10.1063/1.99089.

[52] A.H.M. Smets, T. Matsui, M. Kondo, High-rate deposition of microcrystalline silicon p-i-n solar cells in the high pressure depletion regime, J. Appl. Phys. 104 (2008) 034508. doi:10.1063/1.2961334.

[53] J.-C. Dornstetter, S. Kasouit, P. Roca i Cabarrocas, Deposition of High-Efficiency Microcrystalline Silicon Solar Cells Using $\mathrm{SiF}_{4} / \mathrm{H}_{2} / \mathrm{Ar}$ Mixtures, IEEE J. Photovolt. 3 (2013) 581-586. doi:10.1109/JPHOTOV.2012.2221683. 
[54] S. Lebib, P. Roca i Cabarrocas, Effects of ion energy on the crystal size and hydrogen bonding in plasma-deposited nanocrystalline silicon thin films, J. Appl. Phys. 97 (2005) 104334. doi:10.1063/1.1913803.

[55] A.S. Abramov, A.I. Kosarev, P. Roca i Cabarrocas, M.V. Shutov, A.J. Vinogradov, Photoinduced effects in RF and VHF a-Si:H films deposited with different ion bombardment, Thin Solid Films. 383 (2001) 178-180. doi:10.1016/S0040-6090(00)01629-1.

[56] M.A. Wank, R. van Swaaij, R. van de Sanden, M. Zeman, Hydrogenated amorphous silicon p-i$\mathrm{n}$ solar cells deposited under well controlled ion bombardment using pulse-shaped substrate biasing, Prog. Photovolt. Res. Appl. 20 (2012) 333-342. doi:10.1002/pip.1157.

[57] J. Palmans, W.M.M. Kessels, M. Creatore, Plasma-surface interaction during low pressure microcrystalline silicon thin film growth, J. Phys. Appl. Phys. 47 (2014) 224003. doi:10.1088/0022-3727/47/22/224003.

[58] G. Bugnon, A. Feltrin, F. Sculati-Meillaud, J. Bailat, C. Ballif, Influence of ion bombardment on microcrystalline silicon material quality and solar cell performances, in: 2008 33rd IEEE Photovolt. Spec. Conf., 2008: pp. 1-4. doi:10.1109/PVSC.2008.4922613.

[59] J.K. Wang, P. Bulkin, I. Florea, J.-L. Maurice, E.V. Johnson, Microcrystalline Silicon Thin Films deposited by Matrix-Distributed Electron Cyclotron Resonance Plasma Enhanced Chemical Vapor Deposition using an $\mathrm{SiF}_{4} / \mathrm{H}_{2}$ Chemistry, J. Phys. Appl. Phys. (2016) 285203. doi:10.1088/0022-3727/49/28/285203.

[60] B. Kalache, A.I. Kosarev, R. Vanderhaghen, P. Roca i Cabarrocas, Ion bombardment effects on microcrystalline silicon growth mechanisms and on the film properties, J. Appl. Phys. 93 (2003) 1262. doi:10.1063/1.1524707.

[61] D.K. Brice, J.Y. Tsao, S.T. Picraux, Partitioning of ion-induced surface and bulk displacements, Nucl. Instrum. Methods Phys. Res. Sect. B Beam Interact. Mater. At. 44 (1989) 68-78. doi:10.1016/0168-583X(89)90690-3.

[62] R. Léal, J.-C. Dornstetter, F. Haddad, G. Poulain, J.-L. Maurice, P. Roca i Cabarrocas, Silicon epitaxy by low-temperature RF-PECVD using $\mathrm{SiF}_{4} / \mathrm{H}_{2} / \mathrm{Ar}$ gas mixtures for emitter formation in crystalline solar cells, in: 2015 IEEE 42nd Photovolt. Spec. Conf. PVSC, 2015: pp. 1-5. doi:10.1109/PVSC.2015.7356052.

[63] R. Brüggemann, Steady-State Photocarrier Grating Method, in: D. Abou-Ras, T. Kirchartz, U. Rau (Eds.), Adv. Charact. Tech. Thin Film Sol. Cells, Wiley-VCH Verlag GmbH \& Co. KGaA, 2011: pp. 177-202. doi:10.1002/9783527636280.ch8. 